\title{
A TRAJETÓRIA DAS POLÍTICAS PÚBLICAS DO IDOSO NO BRASIL: BREVE ANÁLISE
}

\author{
Mariluci Hautsch Willig', Maria Helena Lenardt², Marineli Joaquim Méier ${ }^{3}$
}

\begin{abstract}
RESUMO: O texto tem como objetivo realizar uma análise da trajetória das Políticas Públicas do Idoso no Brasil. A construção deste artigo foi realizada com base na análise e reflexão a respeito de leis, decretos, eventos nacionais e internacionais, textos e artigos concernentes ao tema analisado, publicados no período de 1982 a 2010. Percebe-se que no âmbito internacional são significativas as contribuições das Assembleias Mundiais sobre Envelhecimento para a incorporação do conceito de envelhecimento ativo nas políticas públicas no Brasil. No contexto brasileiro destacam-se as iniciativas do Serviço Social do Comércio e da Sociedade Brasileira de Geriatria e Gerontologia em prol do desenvolvimento das políticas de atenção ao idoso. Constata-se que a capacitação e formação específica em Geriatria e Gerontologia no Brasil são deficitárias e que a legislação brasileira direcionada aos idosos, apesar de bem estruturada e avançada, mostra-se incipiente em sua prática.

PALAVRAS-CHAVE: Idoso; Política de saúde; Envelhecimento da população.
\end{abstract}

\section{THE TRAJECTORY OF PUBLIC POLICIES DIRECTED AT THE ELDERLY IN BRAZIL: A BRIEF ANALYSIS}

\begin{abstract}
The text aimed to carry out an analysis of the trajectory of Public Policies directed at the Elderly in Brazil. This article was constructed based on analysis and reflection considering laws, decrees, national and international events, texts or articles concerning the theme under analysis, published in the period $1982-2010$. It may be noted that in the international ambit, the contributions of the World Assemblies on Ageing are significant for the incorporation of the concept of active ageing into public policies in Brazil. The initiatives of the Commerce Social Service and of the Brazilian Society for Geriatrics and Gerontology, directed at the development of policies for caring for the elderly, stand out in the Brazilian context. It was determined that the capacitation and training in Geriatrics and Gerontology in Brazil are deficient and that Brazilian legislation aimed at the elderly, despite being well structured and advanced, remains incipient in practice.
\end{abstract}

KEYWORDS: Elderly; Health policy; Ageing of the population.

\section{LA TRAYECTORIA DE LAS POLÍTICAS PÚBLICAS DEL ANCIANO EN BRASIL: BREVE ANÁLISIS}

RESUMEN: El texto tiene el objetivo de hacer un análisis de la trayectoria de las Políticas Públicas del Anciano en Brasil. La elaboración de este artículo se realizó con base en el análisis y reflexión acerca de leyes, decretos, eventos nacionales e internacionales, textos y artículos relacionados al tema analizado, publicados en el periodo de 1982 a 2010. Se percibió que son significativas, en el ámbito internacional, las contribuciones de las Asambleas Mundiales sobre Envejecimiento para la incorporación del concepto de envejecimiento activo en las políticas públicas en Brasil. En el contexto brasileño, se destacan las iniciativas del Servicio Social del Comercio y de la Sociedad Brasileña de Geriatría y Gerontología al servicio del desarrollo de las políticas de atención al anciano. Se concluye que la capacitación y formación específica en Geriatría y Gerontología en Brasil son deficitarias y que la legislación brasileña acerca de los ancianos, a pesar de estructurada y avanzada, todavía es incipiente en su práctica.

PALABRAS CLAVES: Anciano; Política de salud; Envejecimiento de la población.

\footnotetext{
${ }^{1}$ Enfermeira. Doutoranda em Enfermagem pelo Programa de Pós-Graduação em Enfermagem da Universidade Federal do Paraná PPGENF UFPR. Membro do Grupo Multiprofissional de Pesquisa sobre Idosos - GMPI.
}

${ }^{2}$ Enfermeira. Doutora em Filosofia. Professora do PPGENF UFPR. Líder do GMPI.

${ }^{3}$ Enfermeira. Doutora em Enfermagem. Professora da Graduação e do PPGENF UFPR.

Autor correspondente:

Mariluci Hautsch Willig

Universidade Federal do Paraná

Rua Alberto Manoel Glaser, 10 - 82600-080 - Curitiba-PR-Brasil

E-mail: familiawillig@terra.com.br
Recebido: 19/05/2012

Aprovado: 03/05/2012 


\section{INTRODUÇÃO}

O crescimento do quantitativo de idosos resulta em múltiplos problemas que se refletem social, política e economicamente

na vida dos idosos e da família, e no âmbito da vida pública", esta conjuntura demanda políticas públicas e programas sociais que abordem esta questão social ${ }^{(1: 30)}$.

A preocupação da atenção pública com os idosos é notória com a promulgação da Política Nacional do Idoso - PNI em 1994, e sua regulamentação em 1996, que reafirmou o contido na Lei Orgânica da Saúde (1990) assegurando os direitos sociais à pessoa idosa, bem como o direito à saúde. Após a tramitação no Congresso Nacional por sete anos, foi sancionado em 2003, o Estatuto do Idoso. O proposto no estatuto avança em relação à PNI, no que concerne aos direitos fundamentais e às necessidades de proteção da população idosa ${ }^{(2-4)}$. A Política Nacional da Saúde da Pessoa Idosa - PNSPI anunciada em 1999, importante dispositivo para o reconhecimento dos direitos sociais já preconizados na PNI, só alcançou seus objetivos, com sua adequação, reformulação, e promulgação em $2006^{(5)}$.

A construção deste texto tem como objetivo realizar uma análise da trajetória das Políticas Públicas do Idoso no Brasil.

\section{A TRAJETÓRIA DAS POLÍTICAS PÚBLICAS DO IDOSO NO BRASIL}

A inclusão dos temas pertinentes ao envelhecimento populacional nas políticas brasileiras ocorreu pela força e influência da sociedade civil, na qual se destacava a criação da Sociedade Brasileira de Geriatria e Gerontologia em 1961 ${ }^{(6)}$. Os grupos de convivência organizados pelo Serviço Social do Comércio - SESC em 1963 foi outra iniciativa, cuja preocupação inicial com o desamparo e a solidão dos aposentados deflagrou uma política dirigida ao idoso ${ }^{(7)}$.

A prestação de assistência específica ao idoso no Brasil se iniciou com a criação em 1975, do Ministério da Previdência e Assistência Social - MPAS, que referenciou as questões direcionadas à saúde, à renda, e prevenção do asilamento. Em 1976 foi instituído o primeiro documento Diretrizes para uma Política Nacional para a Terceira idade que continha normas para uma política social destinada à população idosa ${ }^{(7)}$. As políticas direcionadas à população idosa centradas nos idosos dependentes e vulneráveis começaram a mudar por influência externa, após a realização da I Assembleia Mundial sobre Envelhecimento, realizada em Viena (1982), que propôs a adoção do conceito de envelhecimento saudável. Este conceito foi incorporado à Constituição Federal do Brasil em $1988^{(8-9)}$.

O direito universal e integral à saúde foi conquistado pela sociedade na Constituição de 1988 e reafirmado com a criação do Sistema Único de Saúde (SUS), por meio da Lei Orgânica da Saúde n. 8.080/90. Concomitante à regulamentação do SUS, o Brasil se organizou para responder às crescentes demandas de sua população que envelhece ${ }^{(3,9)}$. A incorporação do conceito de envelhecimento saudável na Carta Magna Brasileira de 1988 representou um grande avanço, contudo, a Constituição transferiu à família o papel de oferecer atenção e cuidados aos idosos: "reconfigura-se a desinstitucionalização do cuidado e seu retorno para o contexto doméstico" ${ }^{(10: 302)}$.

A Política Nacional do Idoso - PNI promulgada em 1994 e regulamentada em 1996 assegurou direitos sociais à pessoa idosa, criando condições para promover sua autonomia, integração e participação efetiva na sociedade e reafirmando o direito à saúde nos diversos níveis de atendimento do SUS. Tem como objetivo a criação de condições favoráveis para alcançar a longevidade com qualidade de $\mathrm{vida}^{(2)}$. Essas condições favoráveis foram interpretadas pelos profissionais da saúde, especialmente enfermeiros, como a necessidade de prover cuidados específicos para esse segmento populacional, alicerçados em estratégias que acrescentam saúde aos indivíduos que têm o privilégio da longevidade.

Para tanto a I Jornada Brasileira de Enfermagem Geriátrica e Gerontológica realizada na cidade de Florianópolis, de 28 a 30 de março de 1996, teve como foco a concepção do cuidado e da especificidade da enfermagem geriátrica e gerontológica, e demarcou o movimento das enfermeiras em prol da disseminação de conhecimentos para o cuidado específico aos idosos ${ }^{(11)}$.

O Estatuto do Idoso aprovado em 2003, destinado a regular os direitos dos idosos, incorpora num único dispositivo leis e políticas anteriormente aprovadas e novas questões como a internação domiciliar e a proteção do idoso em situação de risco social, amplia a resposta do Estado e da sociedade às necessidades da população idosa ${ }^{(4)}$. Os preceitos contidos no Estatuto do Idoso são repercussões do Plano de Ação proposto na II Assembleia Mundial sobre o Envelhecimento, celebrada em Madri em 2002(12).

Em 2006, por influência das decisões tomadas na V Conferência Internacional sobre a Promoção da 
Saúde - México em 2000, os gestores do SUS assumem o compromisso do PACTO PELA SAÚDE, o qual tem como componente o Pacto pela Vida, que inclui como prioridade a saúde do idoso na busca da atenção integral e integrada, promoção do envelhecimento ativo e saudável, implantação de serviços de atenção domiciliar e implantação da Política Nacional de Saúde da Pessoa Idosa ${ }^{(5,13-14)}$.

A PNSPI anunciada em 1999 foi readequada e regulamentada em 19 de outubro de 2006, através da Portaria n. 2528. Apresenta como questão central "recuperar, manter e promover a autonomia e a independência dos indivíduos idosos, direcionando medidas coletivas e individuais de saúde para esse fim, em consonância com os princípios e diretrizes do Sistema Único de Saúde"; o foco dessa política é todo cidadão brasileiro com 60 anos ou mais ${ }^{(5: 2)}$.

\section{AVANÇOS E LIMITAÇÕES DAS POLÍTICAS PÚBLICAS DO IDOSO NO BRASIL}

A legislação brasileira ${ }^{(3-5)}$ direcionada aos cuidados da população idosa se mostra bem estruturada, pois foi construída por profissionais com expertise na temática, dentre esses, muitos enfermeiros contribuíram com seus conhecimentos específicos nesta área. Apesar do significativo atraso para elaborar as políticas públicas, pois foi preciso órgãos, eventos, encontros nacionais e internacionais incitarem os governos da importância da criação e regulamentação das mesmas, em sua configuração condizem com o proposto pelas políticas internacionais notadamente sobre o conceito de envelhecimento saudável e ativo e suas demandas.

Os principais avanços da PNSPI, regulamentada em 2006, consistem na incorporação do conceito de envelhecimento ativo, preconizado pela Organização Mundial da Saúde (2002), na desmistificação da velhice, na valorização da participação dos idosos na vida social e intergeracional ${ }^{(5,12)}$. As questões relativas à educação já referenciada na Política Nacional do Idoso, estabelece as competências do Ministério da Educação e do Desporto, em articulação com órgãos federais, estaduais e municipais de educação, como

o incentivo à inclusão nos programas educacionais de conteúdos sobre o processo de envelhecimento; e de disciplinas de Gerontologia e Geriatria nos currículos dos cursos superiores ${ }^{(2: 3)}$

são reafirmadas na $\mathrm{PNSPI}^{(5)}$.
O conhecimento a respeito do processo de envelhecimento não se faz presente na maioria dos currículos dos cursos de graduação na área da saúde. A pouca difusão dos conhecimentos geriátricos e gerontológicos entre os profissionais de saúde, aliada à falta de sintonia entre as instituições de ensino superior com a nova realidade demográfica e epidemiológica, acarreta escassez de recursos humanos e materiais na atenção aos idosos ${ }^{(15)}$. Isso dificulta uma abordagem interdisciplinar e multidimensional preconizada pela PNSPI.

Associada à necessidade de inserção da disciplina de Geriatria e Gerontologia nas grades curriculares, é preciso construir uma cultura de cuidados aos idosos de alcance nacional de modo que a acessibilidade, o acolhimento, o cuidado integral, e o direito à saúde desta faixa etária ocorram de fato.

\begin{abstract}
Os profissionais que cuidam de idosos precisam estar presentes como pessoas capazes de saber e fazer o cuidado específico do idoso. Do contrário, a capacidade para compreender, responder e se relacionar torna-se limitada ${ }^{(16: 118)}$.
\end{abstract}

A estruturação, elaboração e o lançamento de uma política requer o acompanhamento do processo de implementação por parte dos gestores dessas políticas. Essa etapa requer estratégias e instrumentos de avaliação bastante sensíveis e fidedignos, que busquem apontar dificuldades concretas na execução e providências a deliberar. Pode-se afirmar que as Políticas Públicas referentes à pessoa idosa são inovadoras, embora incipientes nos implementos que permitem levá-las à prática por meio de providências concretas.

Deste modo também se torna um empecilho o conhecimento das políticas direcionadas aos idosos, pois fica restrito aos profissionais de saúde. A informação sobre os direitos e deveres da pessoa idosa abrange todos os cidadãos que terão contato com os idosos, pois a atenção e respeito deverão ocorrer em todo o cenário social frequentado por este segmento populacional.

\section{CONSIDERAÇÕES FINAIS}

A trajetória das Políticas Públicas do Idoso no Brasil mostra que a sua criação ocorreu de forma tardia e morosa, levando um tempo demasiado longo entre a tramitação e sua homologação, sempre influenciadas por eventos nacionais e internacionais.

Constata-se que as políticas são fruto das ações iniciais desenvolvidas pelo Serviço Social do Comércio e pela Sociedade Brasileira de Geriatria e Gerontologia 
que procuravam chamar a atenção do Governo para os problemas enfrentados pelos idosos e a necessidade da criação de políticas específicas para este segmento populacional. As conferências e assembleias internacionais foram determinantes para a promulgação das políticas e para a incorporação do conceito de envelhecimento ativo.

A trajetória aponta também a necessidade da capacitação e formação específica em Geriatria e Gerontologia de profissionais que atuam no atendimento ao idoso, o que ainda é deficitária no Brasil, especialmente aos que cuidam dessa população. Isso se faz necessário para atender o preconizado pelo Estatuto do Idoso e a Política Nacional de Saúde da Pessoa Idosa, e proporcionar efetivamente a atenção e promoção da saúde.

O futuro da população idosa dependerá da implementação adequada das políticas e programas existentes, que favoreçam o acesso a bens e serviços e sua integração e participação na comunidade, de maneira a alcançar um envelhecimento digno e ativo.

\section{REFERÊNCIAS}

1. Carvalho MCBNM. O diálogo intergeracional entre idosos e crianças [dissertação]. Rio de Janeiro (RJ): Pontifícia Universidade Católica do Rio de Janeiro; 2007.

2. Ministério da Saúde (BR). Decreto n. 1948, de 3 de julho de 1996: regulamenta a Lei ${ }^{\circ} 8.842$, sancionada em 4 de janeiro de 1994, a qual dispõe sobre a Política Nacional do Idoso e dá outras providências. Diário Oficial da União, [Internet] 05 jan 1994 [acesso em 10 nov 2010]. Disponível: http://www.planalto.gov.br/ ccivil/leis/18841.htm

3. Brasil. Lei n. 8080, de 19 de setembro de 1990. Dispõe sobre as condições para Promoção, Proteção, e Recuperação da Saúde, a organização e o funcionamento dos serviços correspondentes e dá outras providências. Diário Oficial da República Federativa do Brasil, Brasília, 20 set. 1990. Seção 1.

4. Brasil. Lei n. 10.741 , de $1^{\circ}$ de outubro de 2003. Dispõe sobre o Estatuto do Idoso e dá outras providências. Diário Oficial da União, [Internet] 03 out 2003 [acesso em 08 nov 2010]. Disponível: http://www2.camara.gov. br/legin/fed/lei.pdf

5. Ministério da Saúde(BR). Decreto n. 1948, de 3 de julho de 1996: regulamenta a Lei n ${ }^{\circ} 8.842$, sancionada em 4 de janeiro de 1994, a qual dispõe sobre a Política Nacional do Idoso e dá outras providências. Diário Oficial da União, [Internet] 05 jan 1994 [acesso em 10 nov 2010].
Disponível: http://portal.saude.gov.br/portal/arquivos/ pdf $/ 2528 \% 20$ aprova $\% 20 \mathrm{a} \% 20$ politica $\% 20$ nacional $\% 20$ de $\% 20$ saude $\% 20$ da $\% 20$ pessoa $\% 20$ idosa.pdf

6. Camarrano AA, Pasinato MT. O envelhecimento populacional na agenda das políticas públicas. In: Camarano AA, organizador. Os novos idosos brasileiros: muito além dos 60 ? Rio de Janeiro: IPEA; 2004. p. 253-92.

7. Beraldo CC, Carvalho MCBNM. Política social de atenção ao idoso: trabalho social com idosos no SESC. In: Barros Junior organizador. Empreendedorismo, trabalho e qualidade de vida na terceira idade. São Paulo: Edicon; 2009. p. 153-73.

8. Organización Mundial de la Salud. I Asamblea Mundial sobre el Envejecimiento. Viena: World Health Organization; 1982.

9. Brasil. Constituição da República Federativa do Brasil. Senado; 1988.

10. Lenardt MH, Silva SC, Willig MH, Seima MD. O idoso portador da doença de Alzheimer: o cuidado e o conhecimento do cuidador familiar. Rev. min. enferm. 2010;14(3):301-7.

11. Kletemberg DF. A construção da enfermagem gerontológica no Brasil: 1970-1996 [tese]. Florianópolis (SC): Universidade Federal de Santa Catarina; 2010.

12. World Health Organization. II Assembleia Mundial sobre o Envelhecimento. Madri: World Health Organization; 2002.

13. World Health Organization. Organização PanAmericana da Saúde. Quinta Conferência Internacional sobre a Promoção da Saúde - Declaração do México. 5-9 de julho de 2000. Brasília: Organização Pan Americana da Saúde; 2000.

14. Brasil. Portaria n $399 / \mathrm{GM}$ de 22 de fevereiro de 2006. Divulga o Pacto pela Saúde 2006 - Consolidação do SUS e aprova as Diretrizes Operacionais do Referido Pacto. Brasília; 2006.

15. Papaléo Netto M, Yuaso DR, Kitadai FT. Longevidade: desafio no terceiro milênio. O mundo da saúde. 2005;29(4):594-607.

16. Lenardt MH, Willig MH, Shimbo AY, Talmann AEC, Maruo GH. O idoso institucionalizado e a cultura de cuidados profissionais. Cogitare enferm. 2006;11(2):117-23. 